\title{
Usefulness of Fractional Flow Reserve during Routine Clinical Procedures in All-Comer Coronary Artery Disease Patients
}

\author{
Sridhar Kasturi*, Shailender Singh, Vijay Kumar Reddy Shanivaram, \\ Manikandhar Pendyala, Chandrashekar Challa \\ Department of Cardiology, Sunshine Heart Institute, Secunderabad, Hyderabad, Telangana \\ Email: *sridharkasturi@yahoo.com
}

How to cite this paper: Kasturi, S., Singh, S., Shanivaram, V.K.R., Pendyala, M. and Challa, C. (2021) Usefulness of Fractional Flow Reserve during Routine Clinical Procedures in All-Comer Coronary Artery Disease Patients. World Journal of Cardiovascular Diseases, 11, 509-522.

https://doi.org/10.4236/wjcd.2021.1111048

Received: August 16, 2021

Accepted: November 19, 2021

Published: November 22, 2021

Copyright $\odot 2021$ by author(s) and Scientific Research Publishing Inc. This work is licensed under the Creative Commons Attribution International License (CC BY 4.0).

http://creativecommons.org/licenses/by/4.0/

\begin{abstract}
Background: Fractional flow reserve (FFR)-guided interventions, though proved to be safe, continue to be a much-underutilized modality in determining treatment strategy, and data is lacking in Indian population. Objective: We aimed to determine the use of FFR-guided PCI and assess the overall impact on treatment decisions and clinical outcomes in patients with acute coronary syndrome (ACS) or chronic coronary syndromes (CCS). Methods: In this single-center retrospective and prospective observational study, FFR had been performed for the evaluation of treatment reclassification and clinical outcomes, as per physician's clinical practice. Results: Data was obtained for 250 subjects (mean age $60.45 \pm 9.6$ years) with 324 lesions. The treatment plan based on angiography alone changed in $28 \%$ of lesions post-hyperemic FFR. The initial treatment plan based on angiography vs. the final treatment plan post-FFR $(>0.80)$ was medical management $56.5 \%$ vs. $66.0 \%$; CABG $11.1 \%$ vs. $7.7 \%$; and PCI $32.4 \%$ vs. $26.2 \%$. In subjects initially assigned to medical management, $14 \%$ had changed to PCI, and for subjects initially assigned to PCI, $44 \%$ had changed to medical therapy. Receiver operating characteristics (ROC) curve analysis revealed a good correlation between a resting FFR value of $<0.87$ and hyperemic FFR value of $<0.80$. The rate of 2 -year major adverse cardiovascular events (MACE) was $0.9 \%$. Conclusion: This study supports the use of FFR in determining treatment strategy in ACS or CCS patients with low MACE. Resting FFR value of $<0.87$ may be an alternative to intracoronary nitroglycerine/adenosine/Nikorandil-induced FFR in predicting positive FFR particularly in hemodynamically unstable patients, and who are intolerant to hyperemic drugs.
\end{abstract}

\section{Keywords}

Angiogram, Fractional Flow Reserve, Percutaneous Coronary Intervention, 
Coronary Physiology

\section{Introduction}

Coronary angiography (CA) is considered the standard technique for guiding percutaneous coronary intervention (PCI) in patients with myocardial ischemia. Myocardial ischemia is a crucial risk factor among patients with multi-vessel coronary artery diseases [1] [2]. Evidence shows that decisions pertaining to coronary stenoses revascularization should be taken not only based on angiographic results but also considering non-invasive or invasive indication of reversible myocardial ischemia [3]. Controversies still exist about performing PCI in angiographically significant but functionally non-significant stenosis [4].

Fractional flow reserve (FFR) has been considered an effective index and gold standard to assess the physiological lesions and detect myocardial ischemia [1]. It is defined as the ratio of maximum blood flow in a stenotic coronary artery to maximum blood flow in a normal artery without stenosis as measured using a coronary pressure wire during invasive coronary angiography [2]. The FFR value in a normal coronary artery is 1.0. An FFR value of 0.80 implies coronary stenosis probability to trigger myocardial ischemia with greater than $90 \%$ accuracy [5]. The FFR provides more specific information and has a better spatial resolution. In FFR, every artery is examined individually, and masking of one ischemic zone by another is avoided. Some observational studies have suggested that worse clinical outcomes associated with stenosis deferred revascularization with lower FFR values than higher FFR values [6] [7].

The European Society of Cardiology guidelines (2010) have incorporated FFR as a class I recommendation into current PCI techniques [8]. The American Heart Association/American College of Cardiology guidelines (2011) have given class IIa recommendation for FFR [9]. The American College of Cardiology (2017) has recommended FFR among patients with stable ischemic heart disease (SIHD) for revascularization [10]. In the FAME (Fractional Flow Reserve Versus Angiography in multi-vessel Evaluation) study, there was a significant reduction in the mortality and myocardial infarction (MI) rates at two years in the FFR-guided group (8.4\%) compared with the angiography-guided group (12.9\%) $(\mathrm{p}=0.02)$ [1]. The RIPCORD study revealed that after FFR, there was a $26 \%$ change in the management plan (medical management, coronary artery bypass grafting [CABG], and percutaneous coronary intervention [PCI]) among stable coronary artery disease (CAD) population. Furthermore, the number of vessels with significant coronary disease changed in $32 \%$ of the cases after FFR disclosure [11].

For patients with multivessel disease (MVD), minimal use of stents through the PCI intervention needs to be achieved for complete relief of myocardial ischemic symptoms. Improved health and economic outcomes in terms of qual- 
ity of life and treatment expenditure have been demonstrated in patients undergoing FFR by deferring PCI and other surgical revascularization treatments [12]. However, multiple studies have reported conflicting decisions between the usage of angiography and FFR-guided interventions with the significant reclassification of treatment plans in patients with MVD. Although FFR-guided revascularization is backed by a substantial body of evidence and is cost-effective, it remains underutilized due to a combination of factors such as added procedural time and operator unfamiliarity. In addition, limited studies have been published to understand the treatment plan changes using coronary angiography and FFR in India. The purpose of this study is to understand the routine use of FFR in clinical practice. The study aimed to determine the reclassification rates of coronary revascularization strategy after performing FFR in addition to diagnostic angiography. The study also assessed the impact of FFR-guided intervention on treatment decisions and clinical outcomes.

\section{Material and Methods}

\subsection{Study Design and Population}

This study was a single-center, open-label, retrospective and prospective observational study. The data were collected between October 2015 and March 2020 with a median follow-up of 27 months. Patients included in the study were as follows: 1) patients aged eighteen years or older at the time of procedure; 2) non-culprit vessel assessment of patients presenting with ST-elevation myocardial infarction (STEMI), non-ST-elevation myocardial infarction (NSTEMI), unstable angina, or stable coronary artery diseases; and 3) patients planned to undergo FFR for further PCI consideration, or those who underwent cardiac catheterization. Patients with extremely tortuous or calcified coronary arteries, and with a patent coronary artery bypass graft at the target vessel were not considered for analysis.

\subsection{Procedure}

Baseline characteristics, including demographics (age, gender), clinical parameters (comorbidities, clinical presentation), and routine laboratory tests before the procedures, were recorded.

Angiography was performed according to standard practices. The FFR procedure was performed after the recording of angiographic parameters. In the FFR procedure, a coronary pressure wire (Radi, St Jude Medical, Uppsala, Sweden) was advanced through the coronary artery, distal to the lesion, adequately. The pressure was equalized with the sensor at the tip of the guiding catheter. Maximal coronary hyperemia was triggered with adenosine (140 $\mu \mathrm{g} / \mathrm{kg}$ per min) through a central venous infusion. For all participants, aspirin and clopidogrel were continued for one year.

The treating physicians recorded prior revascularization strategy on angiography before performing the FFR measurements. Then, the final patient revas- 
cularization strategy was recorded after performing FFR measurements. The treatment plan established was medical management (MM), coronary artery bypass surgery (CABG), and PCI. Medical management was considered for an FFR value of $>0.80$, and revascularization was recommended if FFR was less than 0.80 . The cutoff value of 0.80 was selected in line with contemporary guidelines and previous findings [13] [14]. Reclassification of the treatment decision was regarded as "changed" if there was at least one decision change based on FFR for multiple lesions; if none of the decisions have been changed for multiple lesions, the treatment decision was defined as "unchanged".

\subsection{Endpoints and Definitions}

The endpoints determined in the present study were cardiac events, target vessel revascularization (TVR), and target lesion revascularization (TLR). Cardiac death was defined as any death because of a proximate cardiac cause, including cardiac arrest, myocardial infarction, low-output failure, or fatal arrhythmia. Both TVR and TLR were defined according to latest ARC consensus statement [15].

\subsection{Statistical Analysis}

Frequency and percentage change in treatment decisions were presented at the subject level and per lesion level. The following cutoff values were used to categorize a continuous variable into a binary variable. FFR group was defined as "low FFR" if it was equal to or below 0.80. Continuous variables were expressed as mean $\pm \mathrm{SD}$; categorical variables were expressed as absolute numbers and percentages (\%). The receiver-operating characteristic (ROC) area under the curve analysis was used to estimate the diagnostic efficiency of resting FFR value of $<0.87$ in patients with resting FFR value of $>0.80$, and to identify the most appropriate cut-off value corresponding to hyperemic FFR value of $<0.80$. The diagnostic performance of resting FFR was assessed using sensitivity and specificity.

\section{Results}

\subsection{Demographics and Baseline Characteristics}

Two hundred and fifty subjects underwent FFR between October 2015 and March 2020. The mean age was $60.45 \pm 9.6$ years; and 199 (79.6\%) were males. Majority (71.6\%) of the population had a history of hypertension, and more than half were diabetic. Fifty-seven patients $(22.8 \%)$ had a history of prior PCI, while 8 (3.21\%) had a history of previous CABG and 11 (4.4\%) had history of MI. The mean LVEF (\%) was $55.82 \pm 8.4$. One hundred and thirty (52.0\%) subjects presented with unstable angina. Of the 324 target lesions, 185 (57\%) were located in the left anterior descending coronary artery, $41(12.7 \%)$ in right coronary artery, and $50(15.4 \%)$ in left circumflex artery. Key baseline and lesion characteristics are summarized in Table 1. 
Table 1. Baseline and lesion characteristics.

\begin{tabular}{|c|c|}
\hline Demographics & Patients $(\mathrm{N}=250)$ \\
\hline Age (years) $($ mean $\pm S D)$ & $60.45 \pm 9.6$ \\
\hline Female & $51(20.4)$ \\
\hline Male & $199(79.6)$ \\
\hline \multicolumn{2}{|l|}{ Medical history } \\
\hline $\mathrm{DM}$ & $138(55.2)$ \\
\hline HTN & $179(71.6)$ \\
\hline Cerebrovascular accident & $5(2)$ \\
\hline Peripheral arterial disease & $4(1.6)$ \\
\hline Smoking & $33(13.2)$ \\
\hline Previous PCI & $57(22.8)$ \\
\hline Previous CABG & $8(3.2)$ \\
\hline Previous MI & $11(4.4)$ \\
\hline LVEF\% $($ mean \pm SD) & $55.82(8.4)$ \\
\hline \multicolumn{2}{|l|}{ Indication for $\mathrm{PCI}$} \\
\hline Unstable angina & $130(52.0)$ \\
\hline STEMI & $31(12.4)$ \\
\hline NSTEMI & $30(12.0)$ \\
\hline Stable angina & $11(4.4)$ \\
\hline Chest pain & $48(19.2)$ \\
\hline \multicolumn{2}{|l|}{ Lesion characteristics ( $N=324$ lesions) } \\
\hline \multicolumn{2}{|l|}{ Vessels treated } \\
\hline LAD & $185(57.1)$ \\
\hline $\mathrm{RCA}$ & $41(12.7)$ \\
\hline LCX & $50(15.4)$ \\
\hline LM & $10(3.1)$ \\
\hline LMCA-LAD & $12(3.7)$ \\
\hline LMCA-LCX & $5(1.5)$ \\
\hline $\mathrm{OM}$ & $13(4.0)$ \\
\hline Pre-procedure diameter stenosis (mean $\pm \mathrm{SD}$ ) $\mathrm{mm}$ & $61.3 \pm 10.91$ \\
\hline SYNTAX $22-33$ & $24(9.6)$ \\
\hline SYNTAX $>33$ & $8(3.2)$ \\
\hline
\end{tabular}

*All data presented as $\mathrm{n}(\%)$ unless otherwise indicated. BMI: body mass index; CABG: coronary artery bypass grafting; LAD: left anterior descending artery; LVEF: left ventricular ejection fraction; NSTEMI: non-ST-elevation myocardial infarction; LCX: left circumflex; LMCA: left main coronary artery; NTG: nitroglycerine; PCI: percutaneous coronary intervention; RCA: right coronary artery; STEMI: ST-elevation myocardial infarction; SD: standard deviation; DM: diabetes mellitus; HTN: hypertension. 


\subsection{Procedural Characteristics}

Post angiography, medical management was planned in 183 cases, CABG and PCI was planned in $36(11.1 \%)$ and 105 (32.4\%) cases, respectively (Table 2). Non-hyperemic FFR was done in 229 (70.7\%) cases, while adenosine-induced FFR was carried out in 302 (93.2\%) cases, and nitroglycerine-induced FFR in 186 (57.4\%) cases. For adenosine-induced hyperemia, intravenous approach was used in $128(39.5 \%)$ patients and intracoronary approach in 92 (28.4\%) patients, while both approaches were used in 93 (28.7\%) patients. The mean adenosine-induced FFR was $0.83 \pm 0.08$, non-hyperemic FFR value was $0.91 \pm 0.07$, and nitroglycerine-induced FFR was $0.87 \pm 0.08$.

\subsection{Change in Treatment Strategy}

The treatment plan based on angiography alone changed following resting FFR Table 2. Procedural characteristics.

\begin{tabular}{|c|c|}
\hline \multicolumn{2}{|l|}{ Post CAG plan $(\mathrm{N}=324)$} \\
\hline Medical management & $183(56.5)$ \\
\hline CABG & $36(11.1)$ \\
\hline PCI & $105(32.4)$ \\
\hline \multicolumn{2}{|l|}{ Number of stents $(\mathrm{N}=105)$} \\
\hline 1 & $87(82.9)$ \\
\hline 2 & $12(11.4)$ \\
\hline Unknown & $6(5.8)$ \\
\hline \multicolumn{2}{|l|}{ FFR performed } \\
\hline Non-hyperemic FFR & $229(70.7)$ \\
\hline Adenosine & $302(93.2)$ \\
\hline NTG & $186(57.4)$ \\
\hline Nikorandil & $1(0.3)$ \\
\hline \multicolumn{2}{|c|}{ Non-hyperemic FFR value $(n=229)$} \\
\hline$<0.89$ (Positive) & $63(27.5)$ \\
\hline$\geq 0.89$ (Negative) & $166(72.5)$ \\
\hline \multicolumn{2}{|c|}{ Adenosine FFR value $(n=302)$} \\
\hline$\leq 0.80$ (Positive) & $95(31.5)$ \\
\hline$>0.8$ (Negative) & $207(68.5)$ \\
\hline \multicolumn{2}{|l|}{ NTG FFR value $(\mathrm{n}=187)$} \\
\hline$\leq 0.80$ (Positive) & $32(17.1)$ \\
\hline$>0.8$ (Negative) & $154(82.3)$ \\
\hline
\end{tabular}

*All data presented as $\mathrm{n}(\%)$ unless otherwise indicated. CABG: Coronary artery bypass grafting; CAG: coronary angiogram; FFR: fractional flow reserve; NTG: nitroglycerine; PCI: percutaneous coronary intervention. 
disclosure in 78 lesions (38\%) hyperemic FFR in 90 lesions (29.8\%), and both resting and hyperemic FFR in 88 lesions (27.2\%). The initial treatment plan based on initial angiography versus the final treatment plan post-FFR was: medical management in 183 (56.5\%) vs. 214 (66.0\%); CABG 36 (11.1\%) vs. 25 (7.7\%); and PCI 105 (32.4\%) vs. 85 (26.2\%); as shown in Figure 1.

For the subjects initially assigned to medical management based on angiography alone, 14\% (26/183) were subsequently assigned to PCI following FFR disclosure. For the subjects initially assigned to PCI and CABG, $44 \%(46 / 105)$ and $36 \%$ (13/36), respectively, were then assigned to medical therapy following FFR disclosure (Figure 1). The frequency of actual revascularization (CABG + PCI) following FFR disclosure changed from $43.5 \%$ to $34.2 \%$ per lesion (Figure 2).

After positive hyperemic FFR, 74\% of lesions (82/111) underwent PCI; 21.6\%

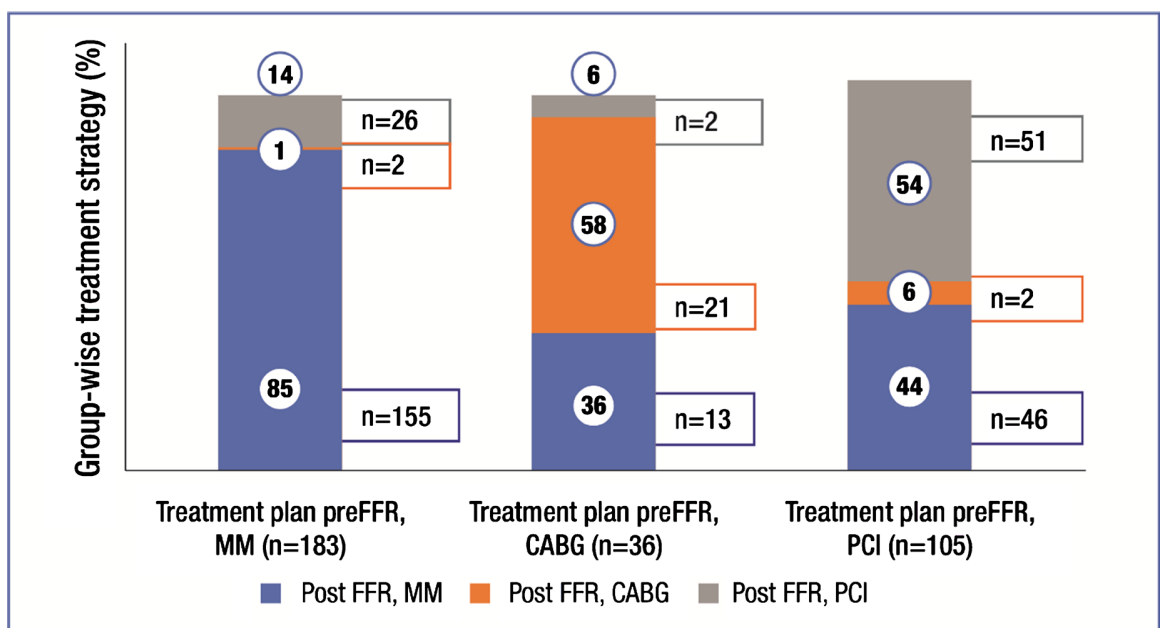

CABG: coronary artery bypass grafting; FFR: fractional flow reserve; MM: medical management; PCI: percutaneous coronary intervention.

Figure 1. Change in treatment plan per lesion in MM, CABG, and PCI groups $(\mathrm{N}=324)$.

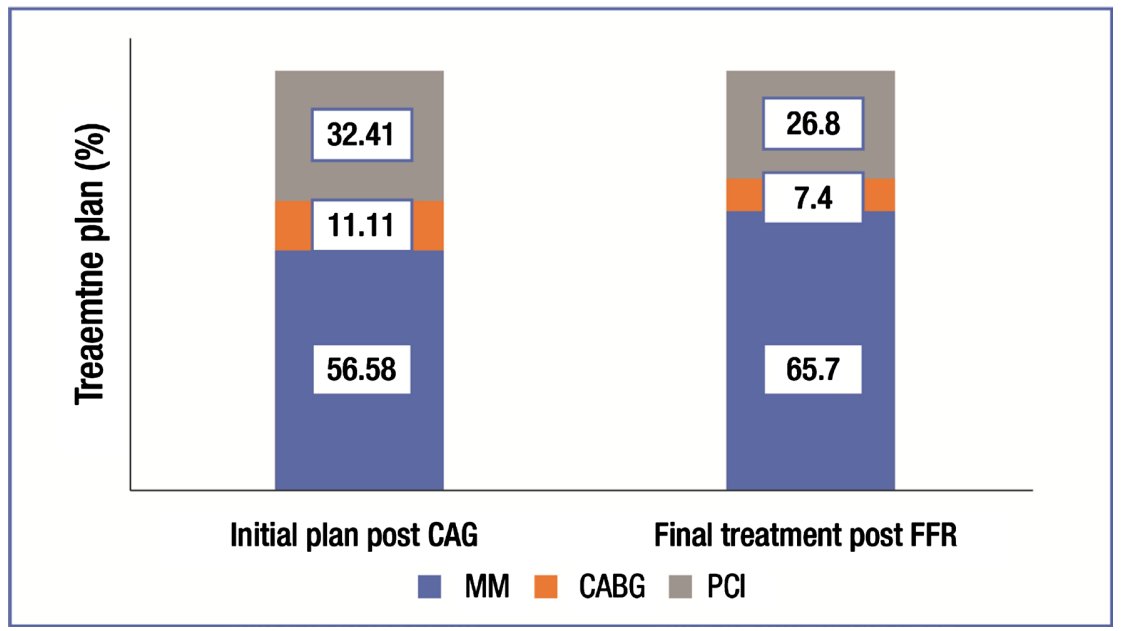

CABG: Coronary artery bypass grafting; CAG: coronary angiogram; FFR: fractional flow reserve; MM: medical management; PCI: percutaneous coronary intervention.

Figure 2. Overall change in treatment plan per lesion $(\mathrm{N}=324)$. 
of lesions (24/111) underwent CABG. Medical management was continued in 99\% of lesions (209/211) in patients who had negative hyperemic FFR values (Table 3).

Table 4 provides a detailed breakdown of the distribution of coronary disease as determined by FFR. Disease status changed in a total of 186 lesions (74.4\%) after FFR data were revealed compared with the assessment based on angiogram alone. The total number of mild CAD cases increased from none to 82 post FFR. There were 89 cases with SVD including 58 cases of mild CAD post FFR. Also, a higher number of number of lesions were redistributed to SVD from DVD post FFR; of 88 TVD lesions determined by CAG, 51 lesions were considered SVD and 14 cases were mild CAD post FFR.

Using an hyperemic FFR cut-off value of $<0.80$ to assess treatment classification, a ROC curve revealed that the resting FFR cut-off value of $<0.87$ in patients with FFR value of $>0.80$ correlated with hyperemic FFR value of $<0.80$; the area

Table 3. Final treatment plan based on hyperemic FFR values.

\begin{tabular}{|c|c|c|c|c|c|c|c|}
\hline \multirow{3}{*}{$\begin{array}{c}\text { Decision by CAG, } \\
\text { n (\%) }\end{array}$} & \multicolumn{7}{|c|}{ After hyperemic FFR } \\
\hline & \multicolumn{3}{|c|}{$>0.80$ (Negative) } & \multicolumn{3}{|c|}{$\leq 0.80$ (Positive) } & \multirow{2}{*}{$\begin{array}{c}\text { No FFR value } \\
\text { PCI }\end{array}$} \\
\hline & MM & CABG & PCI & MM & CABG & PCI & \\
\hline $\mathrm{MM}(\mathrm{n}=183)$ & $154(84)$ & & $1(1)$ & $1(1)$ & $2(1)$ & $24(13)$ & $1(1)$ \\
\hline CABG $(n=36)$ & $13(34)$ & $1(3)$ & & & $20(56)$ & $2(6)$ & \\
\hline \multirow[t]{2}{*}{ PCI $(n=105)$} & $42(40)$ & & & $4(4)$ & $2(2)$ & $56(53)$ & $1(1)$ \\
\hline & 209 & 1 & 1 & 5 & 24 & 82 & 2 \\
\hline
\end{tabular}

*All data presented as $\mathrm{n}(\%)$ unless otherwise indicated. CABG: Coronary artery bypass grafting; CAG: coronary angiogram; FFR: fractional flow reserve; MM: medical management; PCI: percutaneous coronary intervention.

Table 4. Distribution of CAD post FFR.

\begin{tabular}{ccccccccc}
\hline $\begin{array}{c}\text { Vessel Disease } \\
(\mathbf{n}=250)\end{array}$ & SVD & DVD TVD & $\begin{array}{c}\text { LM }+ \\
\text { SVD }\end{array}$ & $\begin{array}{c}\text { LM }+ \\
\text { DVD }\end{array}$ & $\begin{array}{c}\text { LM }+ \\
\text { TVD }\end{array}$ & $\begin{array}{c}\text { MILD } \\
\text { CAD }\end{array}$ & Pre FFR \\
\hline SVD & 22 & & & & & & 58 & 80 \\
DVD & 51 & 23 & & & & & 14 & 88 \\
TVD & 12 & 21 & 19 & & & 6 & 58 \\
LM + SVD & 2 & & & 3 & & & & 5 \\
LM + DVD & 1 & 1 & & 4 & 2 & & 3 & 11 \\
LM + TVD & 1 & 1 & & & 1 & 4 & & 7 \\
LMCA & & & & & & & 1 & 1 \\
Post FFR & 89 & 46 & 19 & 7 & 3 & 4 & 82 & 250 \\
\hline
\end{tabular}

CAD: Coronary artery disease; CAG: coronary angiogram; DVD: dual vessel disease; LMCA: left main coronary artery; LM: left main; FFR: fractional flow reserve; SVD: single vessel disease; TVD: triple vessel disease. 


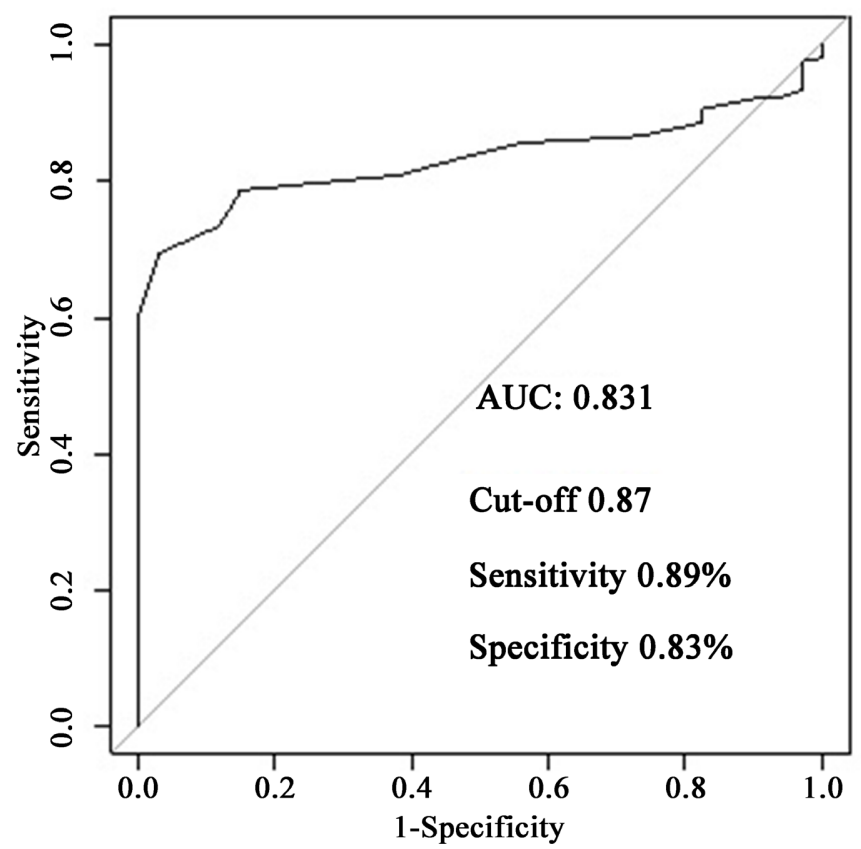

Figure 3. ROC curves of resting FFR values for an FFR cut-off value of 0.80 .

under the ROC curve was 0.831 , indicating good accuracy for the resting FFR cut-off value of $<0.87$. A total of $5 / 46$ cases were found discordant for resting FFR $<0.87$ and positive hyperemic FFR, and 30/180 cases were found discordant for resting FFR $\geq 0.87$ and negative hyperemic FFR. The sensitivity and specificity of resting FFR for the detection of a cut-off FFR value of less than 0.80 were $0.89 \%$ and $0.83 \%$ in treated lesions (Figure 3 ).

\subsection{Clinical Outcomes}

Major adverse cardiac events (MACE) were defined as a composite, including all-cause death, non-fatal myocardial infarction, and TLR/TVR. The MACE for the overall population at 24 months was $0.9 \%$ : death occurred in 3 patients including one patient who was changed to MM from PCI after FFR. There were no cases of TVR, TLR, MI, and cardiac death immediately after intervention or during the follow-up.

\section{Discussion}

This retrospective study demonstrated the safety and feasibility of FFR-guided management in CAD patients with multiple vessel disease and intermediary lesions. Majority of the patients were ACS. The FFR-guided management resulted in a considerably higher change in treatment post FFR.

The use of FFR has been recommended by the European (Class 1A) [8] and US guidelines (Class 2A) [10] [16] for evaluation of angiographic intermediate coronary lesions (50\% to $70 \%$ stenosis) and for guiding revascularization decisions in patients with stable CAD. According to the Society of Cardiovascular Angiography and Interventions, in SIHD, PCI of lesions with FFR $<0.80$ improves 
symptom control and decreases urgent revascularization compared to medical therapy. When FFR $>0.80$ in angiographically intermediate lesions with SIHD, medical therapy is indicated [17]. Accordingly, FFR in the current study was utilized in patients with features of both ACS and SIHD with mean stenosis of 61 $\mathrm{mm}$.

Several single-country registries, such as R3F (French FFR Registry) POST-IT (Portuguese Study on the Evaluation of FFR-Guided Treatment of Coronary Disease), reported that FFR was associated with a high rate of change of the revascularization strategy (38\% overall) [18] [19]. A similar revascularization rate was also observed in the recent IRIS-FFR study [20]. The RIPCORD registry determined the impact of routine FFR at the time of diagnostic CAG on management in stable chest pain patients. Overall, after disclosure of FFR data, management plan based on CA alone was changed in $26 \%$ of patients [11]. In the current study that included $20 \%$ patients with stable angina, an overall change in treatment strategy from initial plan was done in $28 \%$ of procedures post CAG.

A retrospective study in India, FIND, analyzed clinical usefulness, cost-benefit, and medium-term outcomes of FFR-based intervention of intermediary CAD lesions ( $\mathrm{N}=59 ; 81$ vessels). Post FFR, about $40 \%$ of lesions have been spared from unnecessary PCI intervention. Further, for every two patients or three lesions, one stent was avoided with FFR added to angiography. In total, 26 stents were avoided when FFR was used. Similarly, post FFR, only three of six patients required surgery [21]. In a large ambispective study conducted at CMC institute Vellore [22], in India $(\mathrm{N}=400)$, about $80 \%$ of patients had a change in management strategy based on FFR assessment (cut-off of $\leq 0.80$ ). The FFR assessment revealed hemodynamically significant lesions in only $29 \%$ of the total of 477 intermediate coronary lesions; this resulted in the avoidance of stenting strategy in almost one-third of patients referred for PCI (30.5\%). Based on FFR measurement, several clinical management subsets were identified: stent avoidance: $30 \%$ of patients had stent avoidance (1.2 stents saved per patients); stent reduction: $31.3 \%$ of patients had reduction in the number of stents implanted (1.07 stents saved per patient); PCI instead of CABG: $10 \%$ of patients had a change in decision from CABG to multivessel PCI; and CABG instead of PCI: 8.3 of patients had a change in decision from PCI to CABG [21]. In the current study, the percent of final revascularization was $34.2 \%$, a decrease in $10 \%$ of revascularisations planned after initial CAG. Post FFR, total number of dual or more vessel disease reduced from 169 to 79. Importantly, 82 cases of mild CAD were newly determined post FRR, impacting the treatment strategy both pre and post PCI. The number of CABG reduced from 36 to 24, and the number of PCI procedures reduced from 105 to 87 post FFR. While change in CABG post CAG to medical management and PCI post FFR was observed in $36 \%$ and $6 \%$ of lesions, change in PCI post CAG to medical management and CABG was observed in $44 \%$ and $2 \%$ of lesions, respectively. The total number of stents saved 
was 24 post FFR (reduced from 105 post CAG to 81 post FFR).

Previous studies reported adverse events with adenosine with no significant difference between intracoronary and intravenous administration [11] [22]. We did not find any major clinically significant adverse events with adenosine except few minor side effects like bradycardia and hypotension which were managed with IV atropine, IV fluids and in some patients IV inotropes. Moreover, we found that whenever a resting FFR value is $<0.87$ it usually predicts hyperemic FFR value $<0.80$ with intracoronary nitroglycerine/adenosine/Nikorandil in majority of patients, and this may be considered as one of the indicators to predict positive FFR test. We feel this finding would be an additional parameter to make decision in patients with clinically unstable status, and who are intolerant to hyperemic drugs which might save time and cost. However, this should be confirmed in future multiple randomized trials.

Several real-world studies noted that FFR-guided treatment was associated with a positive long-term outcome with a decreased reduction in MACE events [23] [24]. The overall 24-month clinical outcome (MACE) rate is shown to be $4.7 \%$ which is comparable to the previous findings from historical studies [25] [26]. Similar to our study, an observational study in Indian setting showed that at 21-median follow-up, the composite endpoint of cardiac death, nonfatal MI, objective evidence of ischemia, and ischemia-driven revascularization in the vessels assessed by FFR occurred were observed in $0.9 \%$ of patients [21].

\section{Conclusion}

In conclusion, the use of FFR in this observational study considerably changed the treatment plan compared to only angiogram. Based on the outcomes, it can be suggested that FFR-guided management is safe and feasible to guide revascularization decisions of both ACS and stable CAD patients and might benefit Indian patients with multiple vessel disease and intermediate/borderline lesions. Further, long-term prospective studies are needed to establish the safety and feasibility of FFR-guided revascularization in ACS and stable CAD patients.

\section{Limitations}

Though our study included larger population with ACS compared to other studies in Indian settings, our study is limited by observational design without control arm.

\section{Funding}

The study has been funded by St Jude Medical India Pvt Ltd (now Abbott). The funding agency has no role study, analysis and interpretation of results.

\section{Acknowledgements}

The authors would like to thank you BioQuest Solutions Pvt Ltd for editorial services. 


\section{Conflicts of Interest}

The authors declare no conflicts of interest regarding the publication of this paper.

\section{References}

[1] Pijls, N.H., Fearon, W.F., Tonino, P.A., Siebert, U., Ikeno, F., Bornschein, B., et al. (2010) Fractional Flow Reserve versus Angiography for Guiding Percutaneous Coronary Intervention in Patients with Multivessel Coronary Artery Disease: 2-Year Follow-up of the FAME (Fractional Flow Reserve Versus Angiography for Multivessel Evaluation) Study. Journal of the American College of Cardiology, 56, 177-184. https://doi.org/10.1016/j.jacc.2010.04.012

[2] Pijls, N.H., De Bruyne, B., Peels, K., Van Der Voort, P.H., Bonnier, H.J., Bartunek, J., et al. (1996) Measurement of Fractional Flow Reserve to Assess the Functional Severity of coronary-Artery Stenoses. New England Journal of Medicine, 334, 1703-1708. https://doi.org/10.1056/NEJM199606273342604

[3] Zimmermann, F.M., Ferrara, A., Johnson, N.P., van Nunen, L.X., Escaned, J., Albertsson, P., et al. (2015) Deferral vs. Performance of Percutaneous Coronary Intervention of Functionally Non-Significant Coronary Stenosis: 15-Year Follow-up of the DEFER Trial. European Heart Journal, 36, 3182-3188.

https://doi.org/10.1093/eurheartj/ehv452

[4] Hodgson, J.M. (2014) What Part of the FFR Link Don't We Understand? Journal of the American College of Cardiology, 62, 1655-1657. https://doi.org/10.1016/j.jacc.2014.08.011

[5] Watkins, S., McGeoch, R., Lyne, J., Steedman, T., Good, R., McLaughlin, M.J., et al. (2009) Validation of Magnetic Resonance Myocardial Perfusion Imaging with Fractional Flow Reserve for the Detection of Significant Coronary Heart Disease. Circulation, 120, 2207-2213. https://doi.org/10.1161/CIRCULATIONAHA.109.872358

[6] Lavi, S., Rihal, C.S., Yang, E.H., Fassa, A.A., Elesber, A., Lennon, R.J., et al. (2007) The Effect of Drug Eluting Stents on Cardiovascular Events in Patients with Intermediate Lesions and Borderline Fractional Flow Reserve. Catheterization and Cardiovascular Interventions, 70, 525-531. https://doi.org/10.1002/ccd.21154

[7] Meuwissen, M., Chamuleau, S.A., Siebes, M., de Winter, R.J., Koch, K.T., Dijksman, L.M., et al. (2008) The Prognostic Value of Combined Intracoronary Pressure and Blood Flow Velocity Measurements after Deferral of Percutaneous Coronary Intervention. Catheterization and Cardiovascular Interventions, 71, 291-297. https://doi.org/10.1002/ccd.21331

[8] Neumann, F.J., Sousa-Uva, M., Ahlsson, A., Alfonso, F., Banning, A.P., Benedetto, U., et al. (2019) 2018 ESC/EACTS Guidelines on Myocardial Revascularization. European Heart Journal, 40, 87-165. https://doi.org/10.1093/eurheartj/ehy394

[9] Levine, G.N., Bates, E.R., Blankenship, J.C., Bailey, S.R., Bittl, J.A., Cercek, B., et al. (2012) 2011 ACCF/AHA/SCAI Guideline for Percutaneous Coronary Intervention: Executive Summary: A Report of the American College of Cardiology Foundation/American Heart Association Task Force on Practice Guidelines and the Society for Cardiovascular Angiography and Interventions. Catheterization and Cardiovascular Interventions, 79, 453-495. https://doi.org/10.1002/ccd.23438

[10] Patel, M.R., Calhoon, J.H., Dehmer, G.J., Grantham, J.A., Maddox, T.M., Maron, D.J. and Smith, P.K. (2017) ACC/AATS/AHA/ASE/ASNC/SCAI/SCCT/STS 2017 Appropriate Use Criteria for Coronary Revascularization in Patients with Stable Ischemic Heart Disease: A Report of the American College of Cardiology Appropri- 
ate Use Criteria Task Force, American Association for Thoracic Surgery, American Heart Association, American Society of Echocardiography, American Society of Nuclear Cardiology, Society for Cardiovascular Angiography and Interventions, Society of Cardiovascular Computed Tomography, and Society of Thoracic Surgeons. Journal of the American College of Cardiology, 69, 2212-2241. https://doi.org/10.1016/j.jacc.2017.02.001

[11] Curzen, N., Rana, O., Nicholas, Z., Golledge, P., Zaman, A., Oldroyd, K., et al. (2014) Does Routine Pressure Wire Assessment Influence Management Strategy at Coronary Angiography for Diagnosis of Chest Pain? The RIPCORD Study. Circulation: Cardiovascular Interventions, 7, 248-255.

https://doi.org/10.1161/CIRCINTERVENTIONS.113.000978

[12] Berry, C., van't Veer, M., Witt, N., Kala, P., Bocek, O., Pyxaras, S.A., et al. (2013) VERIFY (VERification of Instantaneous Wave-Free Ratio and Fractional Flow Reserve for the Assessment of Coronary Artery Stenosis Severity in Everyday Practice): A Multicenter Study in Consecutive Patients. Journal of the American College of Cardiology, 61, 1421-1427. https://doi.org/10.1016/j.jacc.2012.09.065

[13] Kern, M.J., Lerman, A., Bech, J.W., et al. (2006) American Heart Association Committee on Diagnostic and Interventional Cardiac Catheterization, Council on Clinical Cardiology. Physiological Assessment of Coronary Artery Disease in the Cardiac Catheterization Laboratory: A Scientific Statement from the American Heart Association Committee on Diagnostic and Interventional Cardiac Catheterization, Council on Clinical Cardiology. Circulation, 114, 1321-1341. https://doi.org/10.1161/CIRCULATIONAHA.106.177276

[14] van de Hoef, T.P., Meuwissen, M., Escaned, J., Davies, J.E., Siebes, M., Spaan, J.A. and Piek, J.J. (2013) Fractional Flow Reserve as a Surrogate for Inducible Myocardial Ischaemia. Nature Reviews Cardiology, 10, 439-452. https://doi.org/10.1038/nrcardio.2013.86

[15] Garcia-Garcia, H.M., McFadden, E.P., Farb, A., Mehran, R., Stone, G.W., Spertus, J., Onuma, Y., et al. (2018) Standardized End Point Definitions for Coronary Intervention Trials: The Academic Research Consortium-2 Consensus Document. Circulation, 137, 2635-2650. https://doi.org/10.1161/CIRCULATIONAHA.117.029289

[16] Patel, M.R., Calhoon, J.H., Dehmer, G.J., Grantham, J.A., Maddox, T.M., Maron, D.J. and Smith, P.K. (2017) ACC/AATS/AHA/ASE/ASNC/SCAI/SCCT/STS 2016 Appropriate Use Criteria for Coronary Revascularization in Patients With Acute Coronary Syndromes: A Report of the American College of Cardiology Appropriate Use Criteria Task Force, American Association for Thoracic Surgery, American Heart Association, American Society of Echocardiography, American Society of Nuclear Cardiology, Society for Cardiovascular Angiography and Interventions, Society of Cardiovascular Computed Tomography, and the Society of Thoracic Surgeons. Journal of the American College of Cardiology, 69, 570-591.

https://doi.org/10.1016/j.jacc.2016.10.034

[17] Lotfi, A., Jeremias, A., Fearon, W.F., Feldman, M.D., Mehran, R., Messenger, J.C., et al. (2014) Expert Consensus Statement on the Use of Fractional Flow Reserve, Intravascular Ultrasound, and Optical Coherence Tomography: A Consensus Statement of the Society of Cardiovascular Angiography and Interventions. Catheterization and Cardiovascular Interventions, 83, 509-518. https://doi.org/10.1002/ccd.25222

[18] Baptista, S.B., Raposo, L., Santos, L., Ramos, R., Calé, R., Jorge, E., et al. (2016) Impact of Routine Fractional Flow Reserve Evaluation during Coronary Angiography on Management Strategy and Clinical Outcome: One-Year Results of the POST-IT. Circulation: Cardiovascular Interventions, 9, Article ID: e003288. 
https://doi.org/10.1161/CIRCINTERVENTIONS.115.003288

[19] Van Belle, E., Rioufol, G., Pouillot, C., Cuisset, T., Bougrini, K., Teiger, E., et al. (2014) Outcome Impact of Coronary Revascularization Strategy Reclassification with Fractional Flow Reserve at Time of Diagnostic Angiography: Insights from a Large French Multicenter Fractional Flow Reserve Registry. Circulation, 129, 173-185. https://doi.org/10.1161/CIRCULATIONAHA.113.006646

[20] Ahn, J.M., Park, D.W., Shin, E.S., Koo, B.K., Nam, C.W., Doh, J.H., et al. (2017) Fractional Flow Reserve and Cardiac Events in Coronary Artery Disease: Data From a Prospective IRIS-FFR Registry (Interventional Cardiology Research Incooperation Society Fractional Flow Reserve). Circulation, 135, 2241-2251. https://doi.org/10.1161/CIRCULATIONAHA.116.024433

[21] Sengottuvelu, G., Chakravarthy, B., Rajendran, R. and Ravi, S. (2016) Clinical Usefulness and Cost Effectiveness of Fractional Flow Reserve among Indian Patients (FIND Study). Catheterization and Cardiovascular Interventions, 88, E139-E144. https://doi.org/10.1002/ccd.25517

[22] Thomson, V.S., Varghese, M.J., Chacko, S.T., Varghese, L., Alex, A.G., George, P.V., et al. (2021) Coronary Artery Disease Management and Cost Implications with Fractional Flow Reserve Guided Coronary Intervention in Indian Patients with Stable Ischemic Coronary Artery Disease. Catheterization and Cardiovascular Interventions, 97, 815-824. https://doi.org/10.1002/ccd.28897

[23] Muller, O., Mangiacapra, F., Ntalianis, A., Verhamme, K.M., Trana, C., Hamilos, M., et al. (2011) Long-Term Follow-up after Fractional Flow Reserve-Guided Treatment Strategy in Patients with an Isolated Proximal Left Anterior Descending Coronary Artery Stenosis. JACC: Cardiovascular Interventions, 4, 1175-1182. https://doi.org/10.1016/j.jcin.2011.09.007

[24] Li, J., Elrashidi, M.Y., Flammer, A.J., Lennon, R.J., Bell, M.R., Holmes, D.R., et al. (2013) Long-Term Outcomes of Fractional Flow Reserve-Guided vs. Angiography-Guided Percutaneous Coronary Intervention in Contemporary Practice. European Heart Journal, 34, 1375-1383. https://doi.org/10.1093/eurheartj/eht005

[25] Davies, J.E., Sen, S., Dehbi, H.M., Al-Lamee, R., Petraco, R., Nijjer, S.S., et al. (2017) Use of the Instantaneous Wave-Free Ratio or Fractional Flow Reserve in PCI. New England Journal of Medicine, 376, 1824-1834. https://doi.org/10.1056/NEJMoa1700445

[26] Götberg, M., Christiansen, E.H., Gudmundsdottir, I.J., Sandhall, L., Danielewicz, M., Jakobsen, L., et al., for the iFR-SWEDEHEART Investigators (2017) Instantaneous Wave-free Ratio versus Fractional Flow Reserve to Guide PCI. New England Journal of Medicine, 376, 1813-1823. https://doi.org/10.1056/NEJMoa1616540 